\title{
Engineering microbial chemical factories to produce renewable "biomonomers"
}

\author{
Jake Adkins, Shawn Pugh, Rebekah McKenna and David R. Nielsen* \\ Chemical Engineering, School for Engineering of Matter, Transport, and Energy, Arizona State University, Tempe, AZ, USA
}

\section{Edited by:}

Weiwen Zhang, Tianjin University, China

\section{Reviewed by:}

Kesaven Bhubalan, Universiti Malaysia Terengganu, Malaysia Martin Siemann-Herzberg,

University Stuttgart, Germany

*Correspondence:

David R. Nielsen, Chemical

Engineering, School for Engineering of Matter, Transport, and Energy,

Arizona State University, Tempe, AZ 85287-6106, USA.

e-mail:david.r.nielsen@asu.edu
By applying metabolic engineering tools and strategies to engineer synthetic enzyme pathways, the number and diversity of commodity and specialty chemicals that can be derived directly from renewable feedstocks is rapidly and continually expanding. This of course includes a number of monomer building-block chemicals that can be used to produce replacements to many conventional plastic materials. This review aims to highlight numerous recent and important advancements in the microbial production of these so-called "biomonomers." Relative to naturally-occurring renewable bioplastics, biomonomers offer several important advantages, including improved control over the final polymer structure and purity, the ability to synthesize non-natural copolymers, and allowing products to be excreted from cells which ultimately streamlines downstream recovery and purification. To highlight these features, a handful of biomonomers have been selected as illustrative examples of recent works, including polyamide monomers, styrenic vinyls, hydroxyacids, and diols. Where appropriate, examples of their industrial penetration to date and end-product uses are also highlighted. Novel biomonomers such as these are ultimately paving the way toward new classes of renewable bioplastics that possess a broader diversity of properties than ever before possible.

Keywords: bioplastics, biopolymers, monomers, metabolic engineering

\section{INTRODUCTION}

At present, nearly all conventional plastics are derived from nonrenewable natural gas and petroleum resources. Global annual plastics production exceeded 260 million tons in 2009 , accounting for roughly $8 \%$ of total worldwide oil consumption (Thompson et al., 2009). By just 2010, the total mark had grown to 265 million tons, with major producers China at $23.5 \%$ of total production, the European Union at $21.5 \%$, and the rest of Asia contributing another 20\% (Plastics Europe, 2011). North American producers, meanwhile, contributed to nearly $20.5 \%$ of that mark, consuming approximately 331 million barrels of liquid petroleum gases (LPG) and natural gas liquids (NGL) and nearly 11 billion $\mathrm{ft}^{3}$ of natural gas as raw materials in the process (US Energy Information Administration, 2011), in addition to sizable energy demands. All told, in the US, for example, plastics production is responsible for about $4.6 \%$ of total consumption of LPG and NGL, $1.5 \%$ of total natural gas consumption, and $\sim 1 \%$ of total electricity usage. In view of the declining availability of petrochemical feedstocks, the expectation that global plastics production will surpass 297 million tons by 2015 (Global Industry Analysts, 2012), and rising consumer demand for "greener" products, there is increased interest to develop alternative plastics from renewable and sustainable resources.

In contrast to petroleum and natural gas derived plastics, "bioplastics" are produced from the carbon and energy stored in renewable biomass feedstocks. As such, bioplastics offer the promise to reduce dependence on non-renewable oil and natural gas, and can positively impact the carbon cycle by consuming atmospheric $\mathrm{CO}_{2}$ (a greenhouse gas) during biomass feedstock cultivation. As the global demand for bioplastics is predicted to triple by 2015 to reach $>1$ million tons per year to represent a \$2.9 billion market (Freedonia Group, 2009), this field is clearly ripe for opportunity and advancements. Whereas technologies exist to convert biomass to plastics through either chemocatalytic processing or by using microbial biocatalysts, the focus here will strictly be on the latter. Together with other recent and complementary reviews (Erickson et al., 2011; Lee et al., 2011a,b, 2012; Curran and Alper, 2012), this article seeks to illustrate how advancements in metabolic and pathway engineering are leading to the development of novel biocatalysts and, in so doing, they are also helping to shape the future of the bioplastics industry.

\section{NATURALLY-OCCURRING BIOPLASTICS}

A number of naturally-occurring biopolymers produced by microorganisms from renewable resources have been found to be useful as bioplastics. The most notable are polyhydroxyalkanoates, or PHAs, which have been extensively reviewed over the years (Braunegg et al., 1998; Chen, 2009; Keshavarz and Roy, 2010). PHAs are biodegradable, linear polyesters composed primarily of monomer subunits of $(R)$-3-hydroxybutyrate $(3 \mathrm{HB})$ and are produced as carbon and energy storage molecules by numerous different microbes from both simple and complex biomass feedstocks (note that monomers of $3 \mathrm{HB}$ and other $\beta$ hydroxyacids will be discussed in detail below). Well-studied examples of bacterial PHA producers include species of Ralstonia (Reinecke and Steinbuchel, 2009), Bacillus (Singh et al., 2009), 
and Pseudomonas (Rojas-Rosas et al., 2007), as well as phototrophic cyanobacteria (Asada et al., 1999).

Although PHAs are efficiently produced by microbes via naturally evolved biosynthesis routes, expressing the requisite pathway enzymes from various natural producers has also enabled their production at high levels in recombinant Escherichia coli, a more tractable host platform (Schubert et al., 1988). All told, bacteria have been engineered to achieve PHA biosynthesis at up to $80 \%$ of cell dry weight and at productivities as high as $4 \mathrm{~g} / \mathrm{L}-\mathrm{h}$ from substrates such as glucose (Lee et al., 1999). As crystalline and heat resistant polymers, with glass transition and melting temperatures of around $5^{\circ} \mathrm{C}$ and $175^{\circ} \mathrm{C}$, respectively, PHAs are most well poised as replacements to polyethylene (PE) and polypropylene (PP) (Pei et al., 2011). However, unlike PE and PP, the natural biodegradability PHAs ensures that they will not leave a legacy in landfills at their end of use. Commercial interest in PHAs has been growing, with Metabolix (Cambridge, MA), for example, pursuing their large scale development through their Mirel ${ }^{\mathrm{TM}}$ and Mvera $^{\mathrm{TM}}$ brands, which collectively are expected to have applications in the production of fibers, films, and coatings, as well as for molded and extruded products.

In spite of numerous advantages, PHA production also suffers from other inherent shortcomings which may ultimately impede their long-term and wide-spread utility. For instance, while their biodegradable nature can help reduce municipal waste, this attribute renders PHAs unsuitable for use in applications requiring long term durability and/or environmental exposure. As all PHAs are thermoplastic polyesters the achievable range of physicochemical and material properties, though diverse, is inherently limited. PHA chain length and purity are difficult to tune and control with high quality assurance in an in vivo setting. Lastly, as they are macromolecules, PHAs do not readily diffuse out from cells, but rather accumulate intracellularly as cytosolic inclusion bodies. Thus, since PHAs can only be harvested after the microbial biocatalyst is lysed, prospects for the continuous bioprocessing of PHAs remain unviable.

Another import class of bioplastics that microorganisms naturally produce are those that can be derived from sugars. For example, select strains of Acetobacter, most notably A. xylinum, are capable of producing high quality cellulose by polymerizing linear chains of $\beta$-1,4-glucan (Krystynowicz et al., 2002). Natural cellulose polymers are most attractive due to their inherent biodegradability. Today, most high-grade cellulose is extracted from agricultural sources, for example, fast growing trees or cotton linters. Bacterial cellulose is an attractive alternative, however, because it is free of lignin and hemicelluloses and, with a molecular weight 100-fold lower than plant cellulose, it also possesses greater mechanical strength (Czaja et al., 2006). After synthesizing linear $\beta$-1,4-glucan chains and secreting them through pores in their outer membrane, their assembly into microfibril bundles then takes place outside the cell (Ross et al., 1991). Thus, in contrast to PHAs, bacterial cellulose is more amenable to downstream recovery and purification; however, just as PHAs, it still suffers from the same quality assurance and quality control concerns. Nevertheless, bacterial cellulose has found many successful commercial applications. For example, bacterial cellulose is used in Brazil by BioFill Produtos Biotecnologicos in their line of medical films (Biofill ${ }^{\circledR}$, Bioprocess ${ }^{\circledR}$, and Gengiflex ${ }^{\circledR}$ ) (Hoenich, 2006), whereas Xylos Corp. (Langhorne, PA) also uses it to produce a line of wound care products (XCell ${ }^{\circledR}$ ) (Czaja et al., 2006).

\section{NATURALLY-OCCURRING BIOMONOMERS}

Limitations associated with naturally-occurring bioplastics have motivated a recent shift in focus to the alternative production of "biomonomers." Biomonomers are small molecules (i.e., monomeric subunits) that can undergo ex situ chemocatalytic polymerization to produce plastics. This strategy offers several distinct advantages. First, since most biomonomers are often naturally excreted from microorganisms the need for cell collection and lysis is eliminated, greatly reducing operating expenditures and facilitating downstream product recovery. Polymerization of biomonomers in highly controlled chemocatalytic environments leads to bioplastics with finely tuned and predictable properties and at high purities to satisfy quality control specifications. Lastly, the ability to co-polymerize biomonomers with other desired monomers (biologically or otherwise derived) increases the diversity of plastics that can be produced from renewable resources, widening the range of achievable chemistries and material properties.

In general, there are two classes of biomonomers of industrial interest. The first can be produced from natural metabolites with the aid of a few simple catalytic post-processing steps. For example, the natural fermentation product ethanol can undergo dehydration to ethylene over a solid acid catalyst (Takahara et al., 2005; Hu et al., 2010), before later being polymerized to poly(ethylene) or its co-polymers. Braskem is taking this approach to convert sugarcane-derived ethanol to bioplastics in Brazil (Phillips, 2008). The second class of biomonomers, which will be the central focus of this review, are those metabolites that themselves are directly suitable for polymerization into bioplastics. Wherever possible, the microbial production of "drop in compatible" biomonomers by this approach is advantageous because, as illustrated in Figure 1, it ensures a seamless interface between emerging biotechnologies and the existing polymer industry. This strategy enables decades of technological expertise and existing process infrastructure to be efficiently leveraged, and effectively

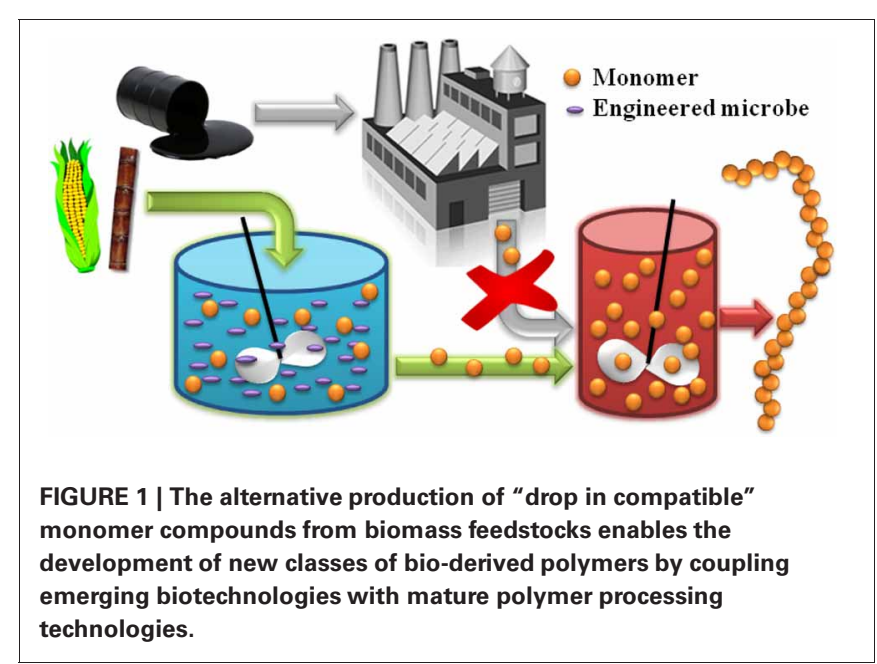


allows conventional chemical and plastics processing to "pick up where biology leaves off."

The most prominent example of a naturally-occurring biomonomer is perhaps $L(+)$-lactic acid, whose polymerization leads to the polyester poly(lactic acid), or PLA. $L(+)$-Lactic acid is a natural fermentation product of numerous microbes, of which prominent examples include lactic acid bacteria (including numerous Lactobacilli sp.) and filamentous fungi (Kosakai et al., 1997; Zhou et al., 1999). As microbial lactic acid production has been extensively reviewed in the past (Wee et al., 2006; Reddy et al., 2008), it will not be addressed in detail here. It is worth noting, however, that $E$. coli been engineered to overproduce both $L(+)$ - (Zhou et al., 1999) and $D(-)$ - (Zhou et al., 2003; Mazumdar et al., 2010) stereroisomers of lactic acid as optically pure products. This is important because lactic acid stereochemistry greatly controls relevant physical properties of PLA including, for example, crystallinity and in turn melting point (Lunt, 1998; Sodergard and Stolt, 2002). In a related and interesting study, Lee and coworkers recently engineered E. coli for the direct in vivo production of PLA by modifying the substrate specificity of PHA synthase 1 of a Pseudomonas sp. and promoting the production of lactyl-CoA, the monomer precursor, by introducing an evolved propionate CoA-transferase from Clostridium propionicum (Jung et al., 2010; Yang et al., 2010). However, just as PHA is confined within cells, so too is in vivo produced PLA. Thus, it is not yet clear how easily or well this specific approach will translate to the commercial scale. Today, NatureWorks LLC (Minnetonka, MN) already produces $>20$ different grades of their Ingeo ${ }^{\mathrm{TM}}$ PLA bioplastics with structures that range from amorphous to crystalline and uses spanning from films to foams. Like PHAs, PLA continues to be a desirable target due in large part to its biodegradability.

A second naturally-occurring biomonomer that has been extensively investigated to date is succinic acid. This 4-carbon diacid is a natural fermentation product of numerous bacteria, including Actinobacillus succinogenes, Anaerobiospirillum succiniciproducens, and Mannheimia succiniciproducens, which have been reviewed elsewhere (Song and Lee, 2006). Moreover, E. coli's metabolism has again also been extensively engineered to overproduce this minor fermentation product to near theoretical yields (Thakker et al., 2012). Succinic acid is particularly useful for producing both polyesters and polyamides, and the first commercial bioplastics derived from this biomonomer will likely be polyamide-5,4 (Qian et al., 2009) and/or poly(butylene-cosuccinate) (PBS) (Bechthold et al., 2008), a biodegradable thermoplastic suitable for extrusion, injection molding, thermoforming, and film blowing (Xu and Guo, 2010). As microbial succinic acid production is now becoming a mature technology, several producers, including both Myriant (Quincy, MA) and BioAmber (Plymouth, $\mathrm{MN}$ ), are now developing commercial scale fermentation processes. BioAmber, for example, currently operates a 3000 ton capacity plant in France, with plans to commission a 17,000 ton facility in Canada in 2013.

\section{ENGINEERING NOVEL BIOMONOMERS}

Despite the potential advantages of using biomonomers to produce renewable plastics, a limited pool of useful naturally-occurring metabolites ultimately constricts the diversity of bioplastics that can be produced by this approach. However, by applying metabolic engineering tools and strategies, de novo metabolic pathway engineering provides the potential to produce non-natural biomonomers, and novel bioplastics, that were never before possible.

Through the rational re-engineering of microbial metabolism "microbial chemical factories" can be constructed to convert biomass feedstocks into chemical products of high value and/or utility as greener and more sustainable alternatives to petrochemicals (Carothers et al., 2009; Martin et al., 2009). This approach has already led to significant and recent improvements to the production of renewable fuels (Atsumi et al., 2008; Atsumi and Liao, 2008; Peralta-Yahya and Keasling, 2010; Schirmer et al., 2010; Steen et al., 2010; Mendez-Perez et al., 2011; Rude et al., 2011), chemicals (Wierckx et al., 2005; Qian et al., 2009; Kind et al., 2010a; Schirmer et al., 2010; Whited et al., 2010), and active pharmaceutical ingredients (Ro et al., 2006; Leonard et al., 2009; Tsuruta et al., 2009; Campbell and Vederas, 2010). As illustrated by several examples in Figure 2, these strategies now offer the same potential to enhance production of novel biomonomers and, as the following selected examples will illustrate, significant progress is already being made in this regard.

\section{POLYAMIDE BIOMONOMERS}

Polyamides (PAs; also known as nylons) are a class of plastics that balance mechanical strength and durability with chemical resistance, and which find extensive use as textiles and mechanical parts. PAs are formed either as homopolymers of amino acids or as co-polymers via condensation of diamines with diacids. The most common commercial PAs are PA-6 (a homopolymer of 6-aminohexanoic acid) and PA-6,6 (a copolymer of adipic acid and 1,6-hexanediamine) which account for more than $85-90 \%$ of the global market, which will approach 6.6 million tons by 2015 (Nexant Chem Systems, 2009). As carbon chain length between amide bonds (typically 2-12) strongly influences material properties, a large diversity of PAs can be generated from a limited monomer pool by a combinatorial approach. Here, however, we specifically focus on recent progress and opportunities related to the microbial production of 4- through 6-carbon linear diamines, amino acids, and diacids (Figure 3 ).

Putrescine, the 4-carbon diamine counterpart to succinic acid, occurs as an amino acid biodegradation product, however no natural over-producers have been isolated to date. Putrescine can be produced by E. coli by two different pathways that stem from either L-arginine (through agmatine by $\mathrm{SpeAB}$ ) or L-ornithine (from L-glutamate by SpeC and SpeF) (Tabor and Tabor, 1985; Igarashi and Kashiwagi, 2000). Several researchers have taken to rationally engineering putrescine overproducing microbes including Qian et al. who, for example, developed a putrescine over-producing E. coli strain by increasing metabolite flux toward L-ornithine (Qian et al., 2009). This was achieved through both promoter replacements and targeted deletions to overcome allosteric and transcriptional regulation of the L-ornithine biosynthesis pathway. Transcriptional repression by L-arginine upon the native promoters $\mathrm{P}_{\arg C B H}, \mathrm{P}_{\text {argD }}$, and $\mathrm{P}_{\arg E}$ was alleviated by their replacement with the strong 


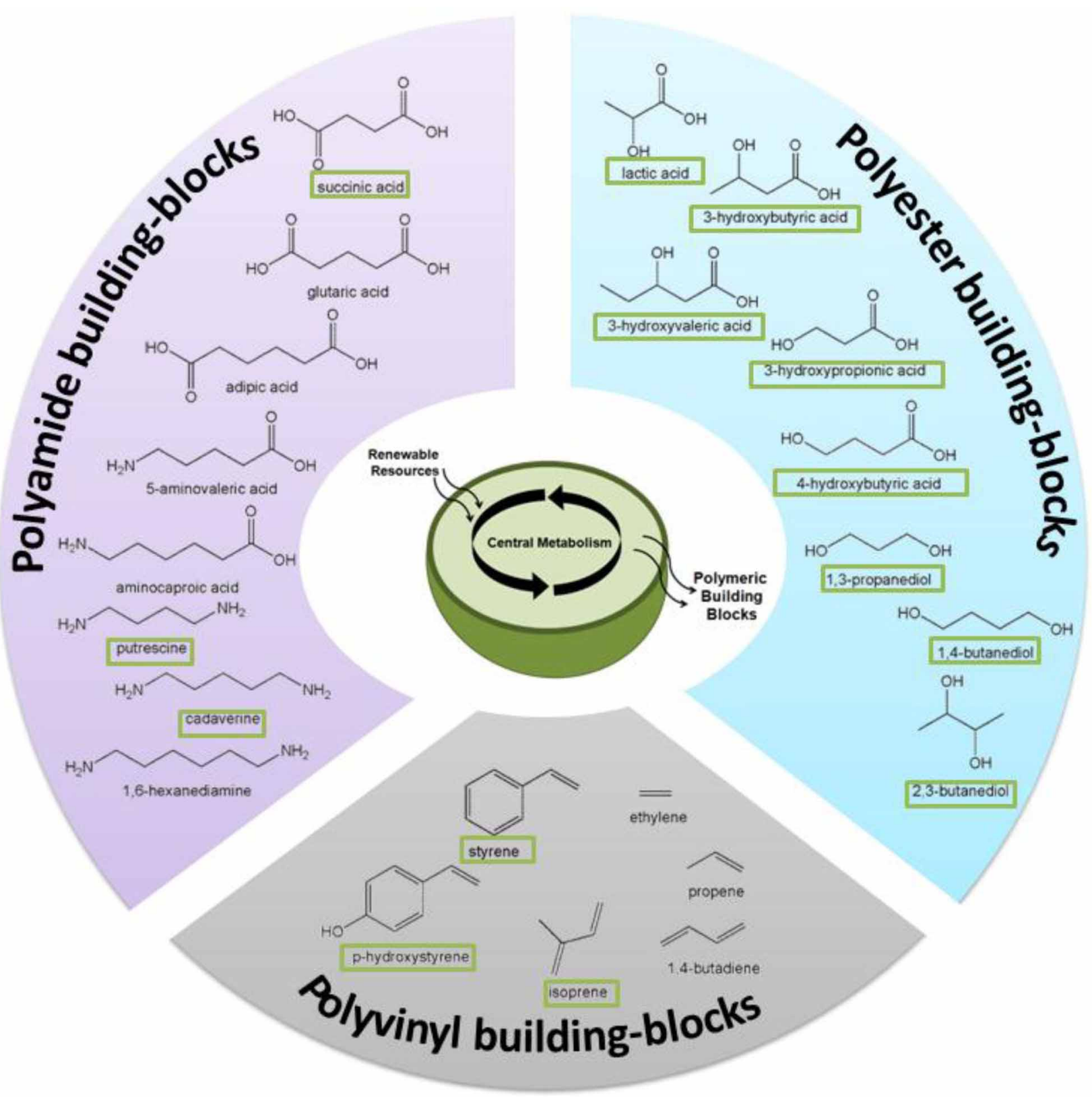

FIGURE 2 | Numerous biomonomers can now be produced as a result of metabolic and pathway engineering; examples discussed in this review are depicted here. "Boxed" names signify molecules that have been produced directly from renewable resources, whereas others have been produced via a hybrid, biocatalytic-chemocatalytic approach. promoter $\mathrm{P}_{t r c}$. Meanwhile, $\mathrm{P}_{\text {speC }}$ and $\mathrm{P}_{\text {sepFpot }}$ were also replaced with $\mathrm{P}_{t r c}$ to relieve feed-back regulation by putrescine and to increase putrescine export through the pot $E$ exporter, respectively. Multiple competing pathways were deleted and the resultant E. coli strain produced $24.2 \mathrm{~g} / \mathrm{L}$ putrescine from glucose in fedbatch cultures (Qian et al., 2009). Corynebacterium glutamicum has also been used for engineering putrescine over-production by both the L-ornithine and L-arginine pathways, however, the L-arginine pathway was $\sim 40$-fold less effective, most likely due to the inhibitory effects of the urea byproduct (Schneider and
Wendisch, 2010). With the L-ornithine pathway, expression of L-ornithine decarboxylase from $E$. coli resulted in putrescine titers of up to $6 \mathrm{~g} / \mathrm{L}$ (Schneider and Wendisch, 2010). Thus, the relative utility of the L-ornithine-derived pathway is conserved between both host platforms investigated. DSM Engineering Plastics (The Netherlands) currently uses putrescine derived from castor oil to produce PA-4,6 and PA-4,10, marketed as Stanyl ${ }^{\mathrm{TM}}$ and EcoPaXX ${ }^{\mathrm{TM}}$, respectively. Microbial putrescine production from simple sugars, however, would add economic and sustainability benefits. 


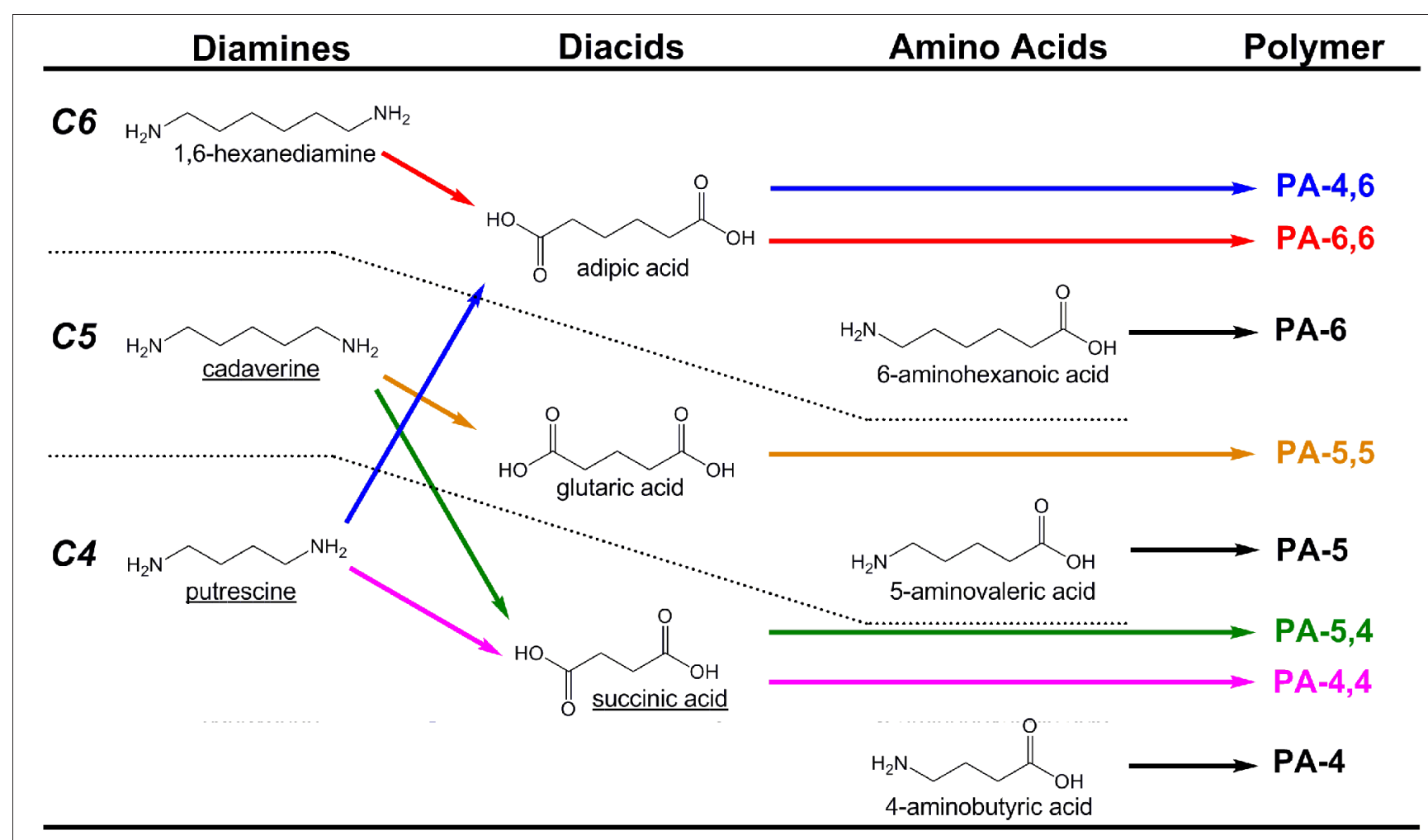

FIGURE 3 | Examples of polyamides (PAs) produced from combinations of C4-C6 diamines, diacids, and amino acids. To date, molecules with names underlined have been produced microbially from renewable resources with the aid of metabolic engineering.

Similar to putrescine, the 5-carbon diamine cadaverine also naturally occurs as an amino acid decarboxylation product, and only at low levels. In this case, it is the decarboxylation of Llysine that forms cadaverine. PAs derived from cadaverine possess such desirable properties as high melting points and low water absorption (Kind and Wittmann, 2011). In addition, PA-5,4 and PA-5,10 have been proposed as bio-based alternatives to several petroleum-derived PAs (Kind and Wittmann, 2011; Qian et al., 2011). Mimitsuka et al. were first to engineer a microbe for cadaverine over-production from glucose by inserting the acid inducible lysine decarboxylase (encoded by cadA) of E. coli into the genome of a L-lysine over-producing strain of C. glutamicum, as seen in Figure 4 (Mimitsuka et al., 2007). The same basic strategy has since been implemented in both E. coli and C. glutamicum which, through additional engineering, have produced cadaverine up to $9.6 \mathrm{~g} / \mathrm{L}$ in E. coli and over $10 \mathrm{~g} / \mathrm{L}$ in C. glutamicum on renewable substrates (Mimitsuka et al., 2007; Tateno et al., 2009; Kind et al., 2010a; Qian et al., 2011). For example, to further enhance production in E. coli, Qian et al. subsequently deleted the native enzymes spermacetyl transferase, spermidine synthase, cadaverine oxidase, and putrescine aminotransferase (encoded by speG, speE, ygjG, and puuA, respectively) which use cadaverine as substrate (Qian et al., 2011). In C. glutamicum, Kind et al. recently showed $l d c C$ of $E$. coli functions better than cadA as a result of differences in pH optima (Kind et al., 2010a), and codon-optimization further aided its function. To increase the availability of L-lysine, lysE was deleted to eliminate losses due to lysine export from C. glutamicum (Figure 4) (Kind et al., 2010b). Genome-wide transcript analysis identified a putative permease (encoded by $c g 2893$ ) that was up-regulated in the presence of cadaverine. While deletion of $c 82893$ reduced cadaverine production by $90 \%$, its over-expression using the strong promoter $\mathrm{P}_{\text {sod }}$ improved cadaverine yields by $20 \%$ (Kind et al., 2011). These results show that if cadaverine can be effectively exported from cells, the negative impacts of allosteric product feed-back inhibition on engineered pathways can be reduced. Most importantly, strategies analogous to those developed here may be of broader utility to the production of other biomonomers and biochemicals.

PA homopolymers are produced from amino acid monomers, a 4-carbon example of which is 4- or $\gamma$-aminobutyrate (GABA). GABA is naturally produced by many organisms from Lglutamate via glutamate decarboxylase. Whereas a microbe that produces GABA directly from glucose has yet to be reported, GABA production from exogenously fed L-glutamate has been investigated in strains engineered to over-express heterologous glutamate decarboxylase. For example, up to $5.5 \mathrm{~g} / \mathrm{L}$ GABA was produced from $10 \mathrm{~g} / \mathrm{L}$ of glutamate by E. coli expressing glutamate decarboxylase (encoded by gadB) and the GABA/Glutamate antiporter (encoded by gadC) (Le Vo et al., 2012). Additionally, the GABA aminotransferase (encoded by gabT) was deleted to prevent endogenous GABA degradation. Future engineering of Lglutamate over-producing hosts will no doubt lead to strains that can achieve high-level GABA production directly from glucose. 


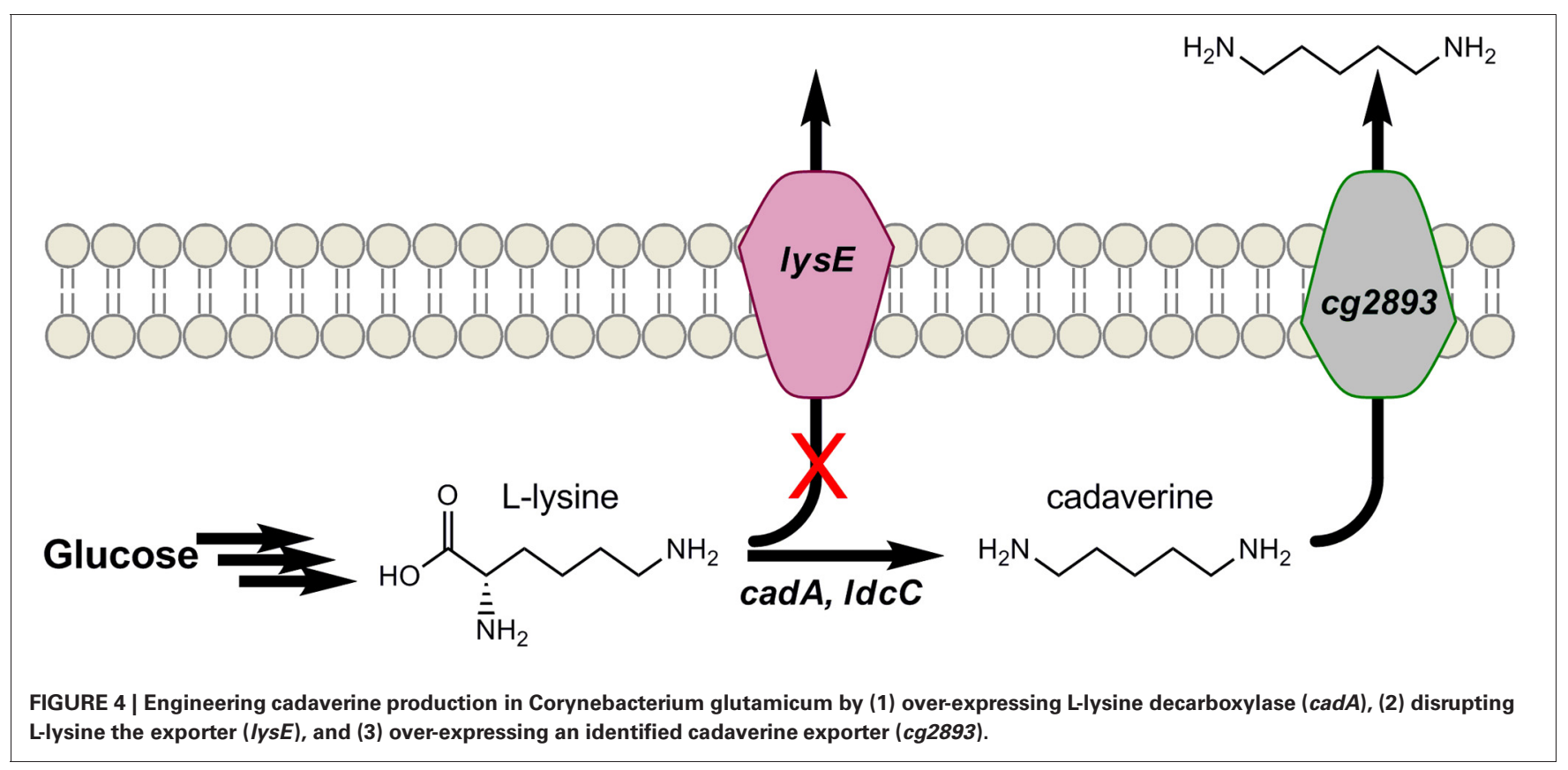

As illustrated in Figure 3, the bio-production of several other useful PA monomers has yet to be realized. Like cadaverine, the 5-carbon diacid glutaric acid is known to be a natural L-lysine degradation product. Numerous Pseudomonas sp., for example, are known to degrade L-lysine through glutaric acid via 5aminovaleric acid (AMV) in the AMV pathway (Revelles et al., 2007). Thus, if the AMV pathway can be functionally reconstructed in a L-lysine over-producing host, renewable routes to PA- 5 and PA-5, 5 would be possible. While PA- 5 has not achieved commercial realization, it is known to possess properties close to PA-4,6 and could serve as a suitable substitute (Bermudez et al., 2000). Meanwhile, the microbial production of three of the most important conventional PA monomers, namely 6-aminohexanoic acid (precursor to PA-6), adipic acid, and 1,6-hexanediamine (both precursors to PA-6,6) has yet to be demonstrated. The closest demonstration was of adipic acid production, from Niu et al. who engineered E. coli to produce cis,cis-muconic acid from glucose at final concentrations of $36 \mathrm{~g} / \mathrm{L}$ (Niu et al., 2002). cis,cisMuconic acid can be hydrogenated over a palladium catalyst at high pressures to yield adipic acid. Certainly, however, a "one pot" biosynthetic approach would be preferred.

\section{STYRENIC VINYLS}

Styrenic vinyls are a family of polymers and co-polymers that use styrene or substituted styrene as a key monomer building-block. Today, nearly $60 \%$ of styrene's global annual production (about six million tons in the US manufacturers and 24 million tons globally), for example, supports plastics production (Sri, 2010). Examples include polystyrene (PS), acrylonitrile-butadienestyrene (ABS), styrene-acrylonitrile (SAN), and styrene butadiene rubber (SBR). Low density PS foams, for instance, are widely used in packaging and as thermal insulators (Thorball, 1967), while the "rubbery" characteristics of SBR make it a natural rubber alternative and the major constituent of tires and many gaskets. Today, all styrenic plastics are produced using petroleum-derived monomers. For example, styrene is produced via ethylbenzene dehydrogenation (Wu et al., 1981). This reaction, however, demands over 3 metric tons of steam per ton of styrene produced, rendering styrene as one of the most energyintensive commodity petrochemicals (US Department of Energy, 2002). The recent engineering of novel enzymatic routes to both p-hydroxystyrene (pHS) and styrene and from glucose (Figure 5), however, may soon enable their renewable production.

The first styrenic biomonomer to be synthesized from renewable resources was pHS (Qi et al., 2007). Its innate optical properties make pHS useful for producing photoresist polymers used in semiconductor manufacturing, for example (Pawlowski et al., 1991). As seen in Figure 5, the engineered pHS biosynthesis pathway stemmed from L-tyrosine as its immediate endogenous precursor. Only two enzymatic steps were then required to convert L-tyrosine to pHS. First, the bi-functional phenylalanine/tyrosine ammonia lyase (PAL/TAL) of the yeast Rhodotorula glutinis catalyzed p-coumaric acid formation. Then, p-coumaric acid was subsequently decarboxylated by phenylacrylate decarboxylase of either Bacillus subtilis (encoded by pdc) or Lactobacillus plantarum (encoded by padC). Initial E. coli strains expressing the pHS pathway achieved final titers as high as only $400 \mathrm{mg} / \mathrm{L}$. Accumulation beyond this mark was severely limited as a result of pHS toxicity imposed on the E. coli host (Qi et al., 2007). To overcome toxicity limitations, the well-known aromatic-tolerant Pseudomonas putida S12 was next investigated as a pHS production platform. Utilizing two strains derived from P. putida S12 to overproduce precursor L-tyrosine as hosts, the pHS pathway was introduced. Due to the innate ability of $P$. putida S12 to degrade numerous aromatic solvents, multiple competing pathway genes were also targeted for deletion. These included both smo, which encodes styrene monooxygenase, and $f c s$, the first gene in the p-coumaric acid degradation pathway. 


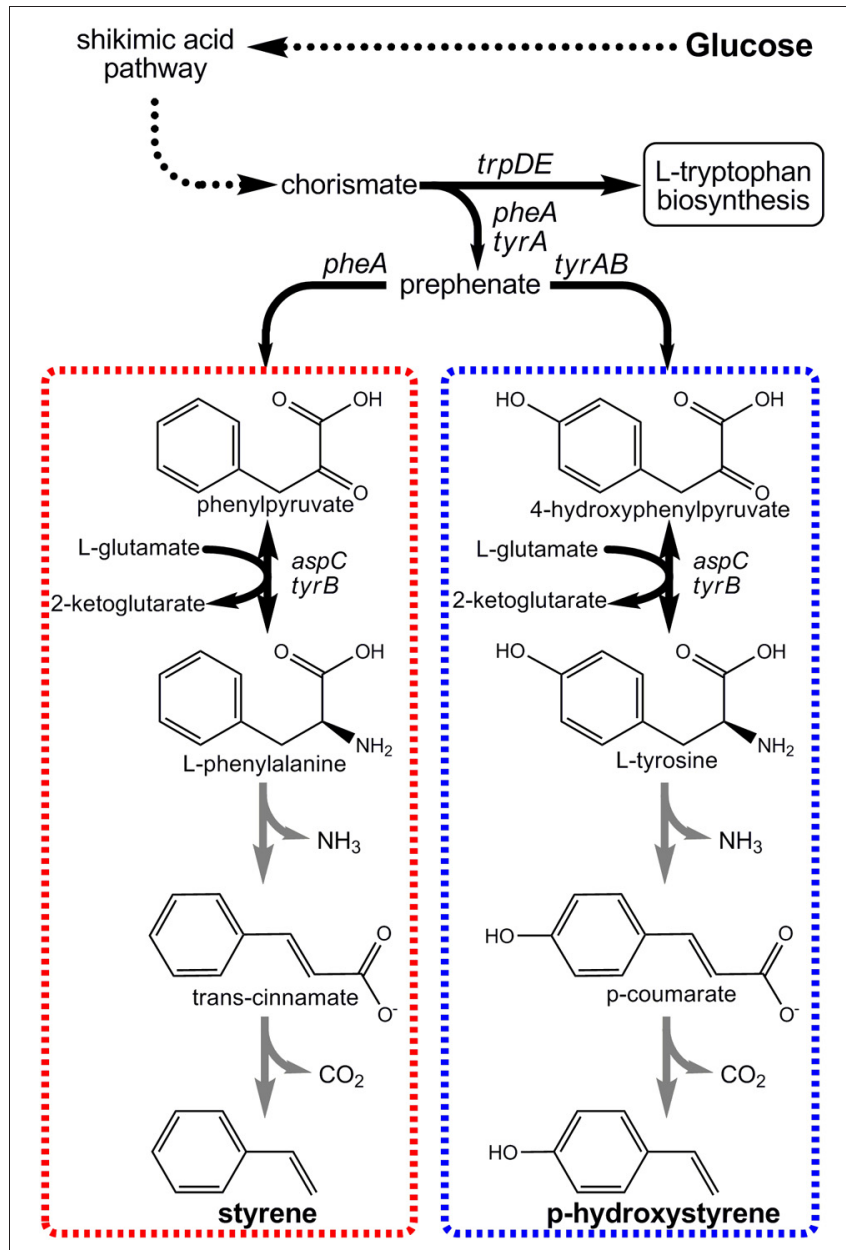

FIGURE 5 | Novel pathways engineered for the production of p-hydroxystyrene and styrene from renewable glucose via aromatic amino acid precursors.

All told, engineered $P$. putida S12 strains were able to reach and tolerate pHS titers as high as $545 \mathrm{mg} / \mathrm{L}$, nearly a $50 \%$ improvement.

More recently, our own group engineered a novel pathway to enable $E$. coli to produce styrene directly from glucose (McKenna and Nielsen, 2011). The styrene biosynthetic pathway is analogous to the pHS pathway (Figure 5), except in that it stems from L-phenylalanine as its endogenous precursor and as such requires different pathway enzyme "parts." In this case, L-phenylalanine ammonia lyase (PAL) first converts L-phenylalanine to trans-cinnamic acid which is then decarboxylated to styrene. Upon screening numerous enzyme candidates, it was ultimately found that PAL2 from Arabidopsis thaliana and FDC1 from Saccharomyces cerevisiae were most effective for these steps, respectively. By over-expressing PAL2 and FDC1 in a L-phenylalanine over-producing $E$. coli host, styrene titers as high as $264 \mathrm{mg} / \mathrm{L}$ were achieved. As with pHS, styrene titers too approached E. coli's toxicity limit $(\sim 300 \mathrm{mg} / \mathrm{L})$ and must similarly be overcome if economical styrene biomonomer production is to be achieved.

\section{HYDROXYACIDS}

In recent years, much attention has been given to the bioproduction of the enantiomerically pure hydroxyacids. Not only is this class of molecules useful as precursors for the production of pharmaceuticals, vitamins, antibiotics, and flavor compounds (Tseng et al., 2009), but hydroxyacids can also serve as biomonomers to derive other renewable polyesters. Hydroxyacids of interest in bioplastics include terminal hydroxyacids such as 3-hydroxypropionate (3HP), as well as the $\beta$ hydroxyacids 3-hydroxybutyrate (3HB) and 3-hydroxyvalerate $(3 \mathrm{HV})$. Each of these hydroxyacid monomers have been produced microbially from renewable resources via pathway engineering.

The shortest of the hydroxyacid monomers is 3HP. 3HP was previously named one of the 12 "Top Value Added Chemicals from Biomass" by the US Department of Energy (2004). In addition to serving as polyester monomer, $3 \mathrm{HP}$ can also be used to produce several other specialty and commodity chemicals through additional chemocatalytic processing (Rathnasingh et al., 2009), including the conventional monomers acrylamide, propiolactone, malonic acid, and 1,3-propanediol. The most notable of which, however, is acrylic acid produced by the dehydration of $3 \mathrm{HP}$. Acrylic acid and its esters are used in polymeric flocculants, dispersants, coatings, paints, and adhesives (Straathof et al., 2005) and represent a $\$ 10$ billion global market. Several companies are now pursuing the commercial development of $3 \mathrm{HP}-$ derived acrylic acid, including, for example, OPX Biotechnologies (Boulder, CO).

While several distinct enzymatic routes have been proposed for microbial 3HP production (Jiang et al., 2009), two have demonstrated the greatest promise to date. The first was a twostep pathway consisting of an adenosylcobalamin dependent glycerol dehydratase to catalyze the dehydration of glycerol to 3-hydroxypropionaldehyde (3HPA), and an aldehyde dehydrogenase to oxidize 3HPA to 3HP (Suthers and Cameron, 2000). Using this pathway, Rathnasingh and coworkers engineered E. coli to produce $38.7 \mathrm{~g} / \mathrm{L} 3 \mathrm{HP}$ in a fed-batch bioreactor with glycerol as substrate. In their strain, glycerol dehydratase (DhaB) from Klebsiella pneumoniae DSM 2026 and $\alpha$-ketoglutaric semialdehyde dehydrogenase (KGSADH) from Azospirillum brasilense were selected (Rathnasingh et al., 2009). A key shortcoming of this approach, however, was the uneconomical requirement for exogenous coenzyme-B12 supplementation. To address this limitation, E. coli was later engineered to produce $3 \mathrm{HP}$ from glucose in a coenzyme-B12-independent manner. This second 3HP pathway consisted of over-expressing the acetyl-CoA carboxylase and biotinilase genes of $E$. coli K-12 ( $a c c A D B C b)$ to convert endogenously produced acetyl-CoA to malonyl-CoA, and expressing the NADPH-dependent malonyl-CoA reductase gene $(\mathrm{mcr})$ of Chloroflexus aurantiacus DSM 635 to reduce malonyl-CoA to 3HP (Rathnasingh et al., 2012). This second pathway, however, initially suffered from inherent NADPH limitations under aerobic conditions. This was ultimately addressed by co-expressing nicotinamide nucleotide transhydrogenase (pntAB from E. coli) to convert $\mathrm{NADH}$ (the more abundant reducing equivalent) to $\mathrm{NADPH}$, leading to $3 \mathrm{HP}$ titers of up to $0.19 \mathrm{~g} / \mathrm{L}$ (Rathnasingh et al., 2012). 
Although both $3 \mathrm{HP}$ pathways possess their own unique limitations which hinder their industrial potential, these pathways represent platforms to which subsequent improvements can now be made via continued strain development. For example, the B12dependent pathway from glycerol may be well-suited for use in natural organisms which are employed for the industrial production of coenzyme-B12, such as Propionibacterium shermanii or Pseudomonas denitrificans, for example (Martens et al., 2002).

Microbial production of $(R)-3 \mathrm{HB}$ by recombinant $E$. coli was first reported by Gao et al. Their engineered pathway was composed of phaA and phaB from Ralstonia eutropha (a natural $\mathrm{PHB}$ producer), encoding $\beta$-ketothiolase and an $(R)$ specific 3-hydroxybutyryl-CoA ( $R$-3HB-CoA) dehydrogenase, respectively, to convert endogenous acetyl-CoA to $3-\mathrm{HB}-\mathrm{CoA}$ through acetoacetyl-CoA (Figure 6). The $p t b$-buk operon from Clostridium acetobutylicum was lastly co-expressed to convert $R$ 3 -HB-CoA to $R$-3HB (via $R$-3-hydroxybutyryl phosphate), and shake flask titers exceeding $2 \mathrm{~g} / \mathrm{L}$ resulted (Gao et al., 2002). Tseng et al. later built upon these works, adding the ability to produce both $(R)$ - and $(S)$-3HB isomers with high stereoselectivity and increasing product titers (Tseng et al., 2009). Stereoselective control was achieved by utilizing two different enantioselective 3HB-CoA dehydrogenases: $(R)$-selective PhaB from $R$. eutropha and $(S)$-selective Hbd from Clostridium acetobutylicum. It was also demonstrated that the broad-substrate thioesterase II of $E$. coli (encoded by tesB) effectively converted both $(R)$ - and $(S)-3 \mathrm{HB}-\mathrm{CoA}$ to their respective $3 \mathrm{HB}$ isomer products, whereas ptb-buk was (R)-specific (Tseng et al., 2009). In the end, $(R)$ and $(S)-3 \mathrm{HB}$ titers as high as 2.92 and $2.08 \mathrm{~g} / \mathrm{L}$, respectively, were attained. $(R)-3 \mathrm{HB}$ biomonomer, can be used to make biodegradable PHB with well-controlled properties. $(S)$-3HB biomonomer, meanwhile, can be used to produce novel $\mathrm{PHBs}$ with new features and properties.

Prather and coworkers subsequently expanded upon their efforts to produce, for the first time, enantiomerically pure stereoisomers of the 5 -carbon $\beta$-hydroxyacid $3 \mathrm{HV}$ (Tseng et al., 2010). This was achieved using a single renewable substrate (glucose) by first engineering $E$. coli to over-produce precursor propionyl-CoA via manipulation of the native L-threonine biosynthesis pathway. Propionyl-CoA was condensed with acetylCoA via a thiolase displaying broad substrate specificity (BktB of $R$. eutropha). The intermediate product, 3-ketovaleryl-CoA, is the 5-carbon analog to acetoacetyl-CoA in the $3 \mathrm{HB}$ pathway (Figure 6). Two analogous steps were then used for its stereoselective reduction to $(R)$ - or $(S)-3 \mathrm{HV}-\mathrm{CoA}$ and conversion to the respective hydroxyacids. The use of BktB was essential in demonstrating the ability of biomonomer chain elongation at the initial condensation step. One disadvantage to their approach, however,

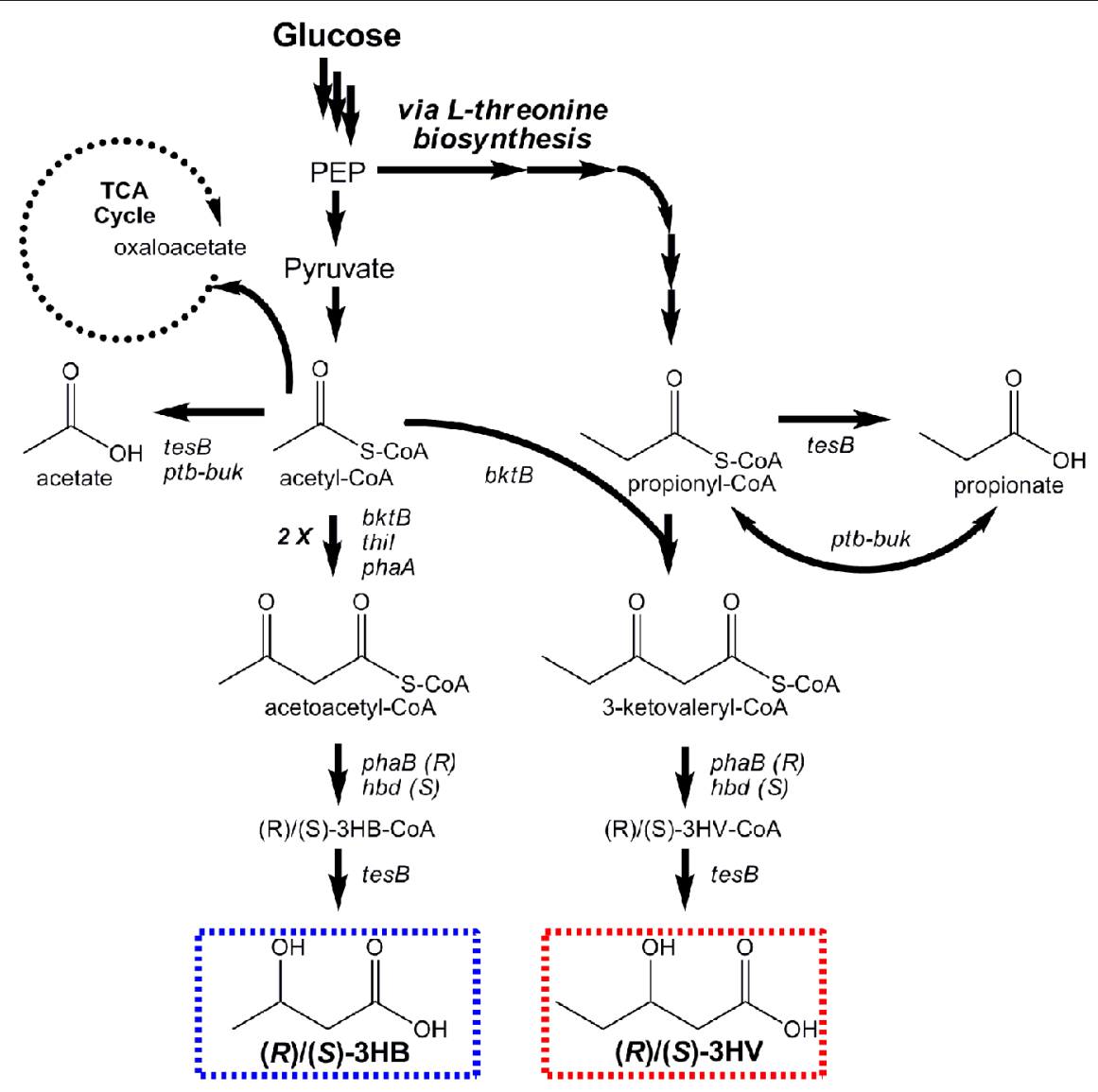

FIGURE 6 | Pathways engineered for stereoselective production of (R)- and (S)-3-hydroxybutyrate and (R)- and (S)-3-hydroxyvalerate from glucose. 
resulted from the promiscuity of BktB, which led to the simultaneous production of acetoacetyl-CoA, and hence 3HB. This realization implies that control over product purity had diminished. Nevertheless, in glucose fed cultures, titers of 0.50 and $0.31 \mathrm{~g} / \mathrm{L}$ of $(R)$ - and $(S)-3 \mathrm{HV}$, respectively, were demonstrated. The subsequent discovery that $\operatorname{NADP}(\mathrm{H})$ limitations of $\mathrm{PhaB}$ reduced conversion to $(R)-3 \mathrm{HV}$ was later overcome using glycerol as substrate, which improved final titers to as high as $0.96 \mathrm{~g} / \mathrm{L}$. Whereas $3 \mathrm{HV}$ production has yet be commercially explored, as a biomonomer it offers the potential develop bioplastics with broader ranges of properties.

\section{DIOLS}

Short-chain diols suitable for bioplastics applications have been produced microbially via both natural and engineered pathways. For example, the four-carbon diol 2,3-butanediol (2,3-BDO) is a natural fermentation product of many microbes, including many species of Klebsiella, Bacillus, and lactic acid bacteria (Voloch et al., 1985). Microbial production of 2,3-BDO by both natural and engineered strains will not be discussed here, however, as it has been extensively reviewed over the years (Garg and Jain, 1995; Celinska and Grajek, 2009; Ji et al., 2010; Nielsen et al., 2010; Ji et al., 2011). Today, companies including LanzaTech (New Zealand) are developing 2,3-BDO as a biomonomer platform following its chemocatalytic conversion to butadiene. More recent efforts have focused on engineering microbes to produce the three-carbon diol 1,3-propanediol (1,3-PDO) and the four-carbon diol 1,4-butanediol (1,4-BDO). Both 1,3-PDO and 1,4-BDO are non-natural metabolites, produced only with the aid of novel, engineered metabolic pathways. Like 2,3-BDO, $1,4-\mathrm{BDO}$ can be similarly converted to butadiene. More importantly, however, both 1,3-PDO and 1,4-BDO are directly useful as biomonomers for the polyesters poly(propylene terephthalate) (PPT) and poly(butylene terephthalate) (PBT). Both PPT and PBT have the potential to steal market share from what is perhaps the oldest polyester, polyethylene terephthalate (PET) (Haas et al., 2005).

While microbial production of 1,3-PDO has been recently and comprehensively reviewed (Nakamura and Whited, 2003; Sauer et al., 2008; Saxena et al., 2009; Celinska, 2010), the engineering of $E$. coli to produce up to $18 \mathrm{~g} / \mathrm{L} 1,4-\mathrm{BDO}$ from glucose (as well as other substrates) was only recently reported for the first time (Yim et al., 2011). Bioproduction of 1,4-BDO was accomplished through the development of two novel pathways (Figure 7), the design of which was facilitated using the SimPheny Biopathway Predictor; a design algorithm that considers chemical structure to predict possible routes from central metabolite precursors to end-product targets (Smolke, 2009). It is also noted that, as seen in Figure 7, both 1,4-BDO pathways include the common intermediate 4-hydroxybutyrate $(4 \mathrm{HB})$, a hydroxyacid. As described above, hydroxyacids are excellent precursors for polyester production. Thus, by further leveraging this technology an additional, non-natural hydroxyacid building block could also be added to the list of potential polyester biomonomers. As their flagship molecule, Genomatica (San Diego, CA) is now developing 1,4-BDO at the commercial scale. Moreover, NatureWorks and BioAmber recently formed a joint venture (AmberWorks) to explore the development of $100 \%$ renewable polyester copolymers of 1,4-BDO and succinic acid (PBS).

\section{CONCLUSIONS}

Whereas most monomer compounds and their respective polymers are presently derived from non-renewable petroleum, by application of metabolic engineering to create novel enzyme

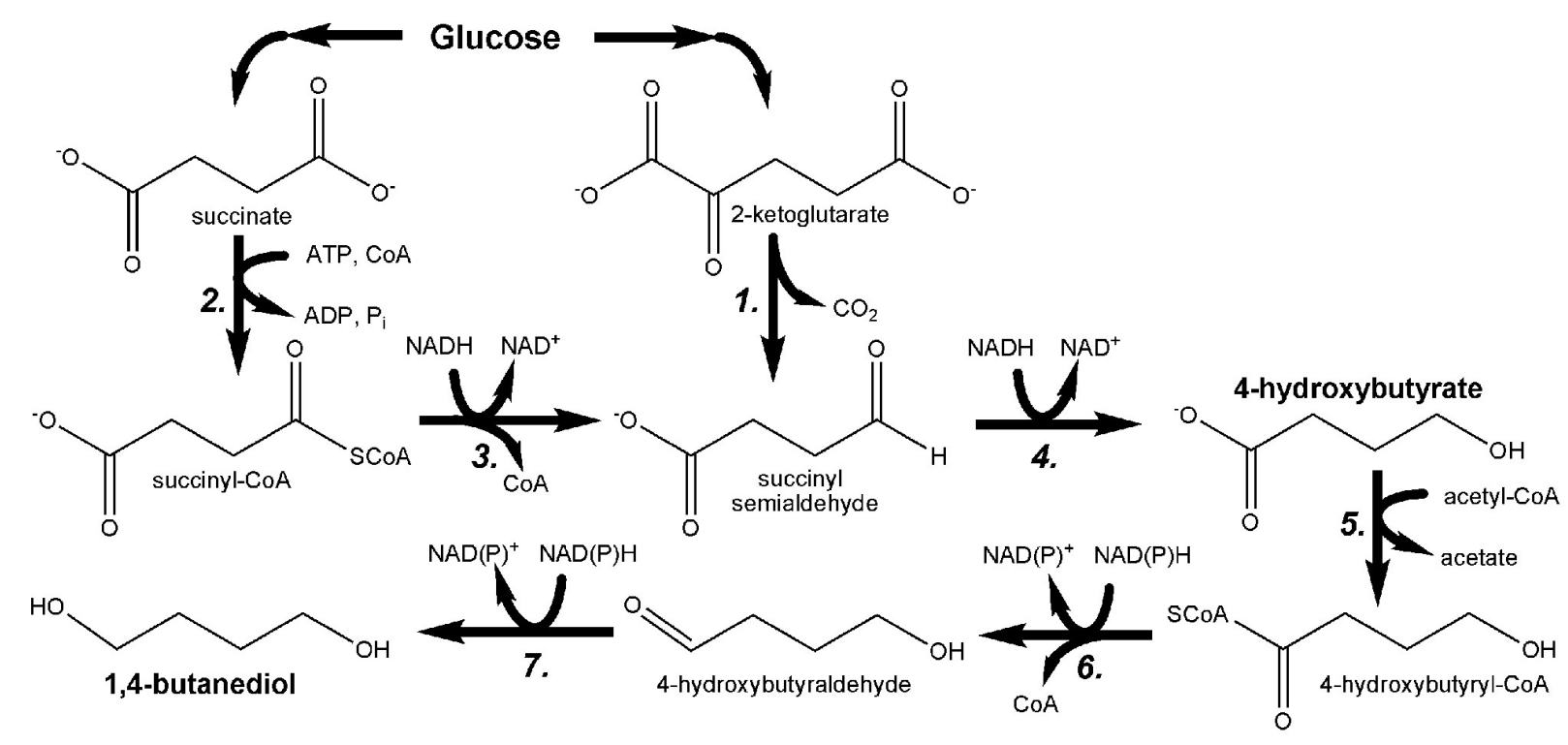

FIGURE 7 | Pathway engineered by Yim et al. for the microbial production of 1,4-butanediol (1,4-BDO) through the hydroxyacid intermediate 4-hydroxybutyrate (4HB). 1. 2-oxoglutarate decarboxylase; 2. succinyl-CoA synthetase; 3. CoA-dependent succinate semialdehyde dehydrogenase; 4. 4-hydroxybutyrate dehydrogenase; 5. 4-hydroxybutyryl-CoA transferase; 6. 4-hydroxybutyryl-CoA reductase; 7. alcohol dehydrogenase. 
pathways this is beginning to change. The rapidly expanding number and diversity of biomonomers will continue to support the development of new markets for "green" and sustainable bioplastics with properties identical to their petroleum-derived counterparts. With the aid of continued research and development, renewable biomonomers will ultimately help to reduce global oil consumption while also promoting greater environmental sustainability.

\section{REFERENCES}

Asada, Y., Miyake, M., Miyake, J., Kurane, R., and Tokiwa, Y. (1999). Photosynthetic accumulation of poly-(hydroxybutyrate) by cyanobacteria - the metabolism and potential for $\mathrm{CO}_{2}$ recycling. Int . J. Biol. Macromol. 25, 37-42.

Atsumi, S., and Liao, J. C. (2008). Metabolic engineering for advanced biofuels production from Escherichia coli. Curr. Opin. Biotechnol. 19, 414-419.

Atsumi, S., Hanai, T., and Liao, J. C. (2008). Non-fermentative pathways for synthesis of branchedchain higher alcohols as biofuels. Nature 451, 86-89.

Bechthold, I., Bretz, K., Kabasci, S., Kopitzky, R., and Springer, A. (2008). Succinic acid: a new platform chemical for biobased polymers from renewable resources. Chem. Eng. Technol. 31, 647-654.

Bermudez, M., Leon, S., Aleman, C., and Munoz-Guerra, S. (2000). Comparison of lamellar crystal structure and morphology of nylon 46 and nylon 5. Polymer 41, 8961-8973.

Braunegg, G., Lefebvre, G., and Genser, K. F. (1998). Polyhydroxyalkanoates, biopolyesters from renewable resources: physiological and engineering aspects. J. Biotechnol. 65, 127-161.

Campbell, C. D., and Vederas, J. C. (2010). Biosynthesis of lovastatin and related metabolites formed by fungal iterative PKS enzymes. Biopolymers 93, 755-763.

Carothers, J. M., Goler, J. A., and Keasling, J. D. (2009). Chemical synthesis using synthetic biology. Curr. Opin. Biotechnol. 20, 498-503.

Celinska, E. (2010). Debottlenecking the 1,3-propanediol pathway by metabolic engineering. Biotechnol. Adv. 28, 519-530.

Celinska, E., and Grajek, W. (2009). Biotechnological production of 2, 3-butanediol-Current state and prospects. Biotechnol. Adv. 27, 715-725.

Chen, G. Q. (2009). A microbial polyhydroxyalkanoates (PHA) based bio- and materials industry. Chem. Soc. Rev. 38, 2434-2446.

Curran, K. A., and Alper, H. S. (2012). Expanding the chemical palate of cells by combining systems biology and metabolic engineering. Metab. Eng. 14, 289-297.

Czaja, W., Krystynowicz, A., Bielecki, S., and Brown, R. M. (2006) Microbial cellulose-the natural power to heal wounds. Biomaterials 27, 145-151.

Erickson, B., Nelson, and Winters, P. (2011). Perspective on opportunities in industrial biotechnology in renewable chemicals. Biotechnol. J. 7, 176-185.

Freedonia Group. (2009). World Bioplastics to 2013. Cleveland, $\mathrm{OH}$ : Freedonia.

Gao, H. J., Wu, Q., and Chen, G. Q. (2002). Enhanced production of D-(-)-3-hydroxybutyric acid by recombinant Escherichia coli. FEMS Microbiol. Lett. 213, 59-65.

Garg, S. K., and Jain, A. (1995). Fermentative production of 2, 3butanediol - a review. Bioresour. Technol. 51, 103-109.

Global Industry Analysts. (2012). Plastics: A Global Outlook. San Jose, CA: GIA.

Haas, T., Jaeger, B., Weber, R., Mitchell, S. F., and King, C. F. (2005). New diol processes: 1, 3-propanediol and 1, 4-butanediol. Appl. Catal. A Gen. 280, 83-88.

Hoenich, N. (2006). Cellulose for medical applications: past, present, and future. Bioresources 1, 270-280.

Hu, Y. C., Zhan, N. N., Dou, C., Huang, H., Han, Y. W., Yu, D. H., and Hu, Y. (2010). Selective dehydration of bio-ethanol to ethylene catalyzed by lanthanum-phosphorousmodified HZSM-5, influence of the fusel. Biotechnol. J. 5, 1186-1191.

Igarashi, K., and Kashiwagi, K. (2000). Polyamines: mysterious modulators of cellular functions. Biochem. Biophys. Res. Commun. 271, 559-564.

Jiang, X., Meng, X., and Xian, M. (2009). Biosynthetic pathways for 3-hydroxypropionic acid production. Appl. Microbiol. Biotechnol. 82, 995-1003.

Ji, X. J., Huang, H., and Ouyang, P. K. (2011). Microbial 2, 3-butanediol production: a state-of-the-art review. Biotechnol. Adv. 29, 351-364.

Ji, X. J., Nie, Z. K., Li, Z. Y., Gao, Z., and Huang, H. (2010). Biotechnological production of 2, 3-butanediol. Prog. Chem. 22, 2450-2461.
Jung, Y. K., Kim, T. Y., Park, S. J., and Lee, S. Y. (2010). Metabolic engineering of Escherichia coli for the production of polylactic acid and its copolymers. Biotechnol. Bioeng. 105, 161-171.

Keshavarz, T., and Roy, I. (2010) Polyhydroxyalkanoates: bioplastics with a green agenda. Curr. Opin. Microbiol. 13, 321-326.

Kind, S., Jeong, W. K., Schroder, H. and Wittmann, C. (2010a). Systemswide metabolic pathway engineering in Corynebacterium glutamicum for bio-based production of diaminopentane. Metab. Eng. 12, 341-351.

Kind, S., Jeong, W. K., Schroder, H., Zelder, O., and Wittmann, C. (2010b). Identification and elimination of the competing $\mathrm{N}$-acetyldiaminopentane pathway for improved production of diaminopentane by Corynebacterium glutamicum. Appl. Environ. Microbiol. 76, 5175-5180.

Kind, S., Kreye, S., and Wittmann, C. (2011). Metabolic engineering of cellular transport for overproduction of the platform chemical 1, 5-diaminopentane in Corynebacterium glutamicum. Metab. Eng. 13, 617-627.

Kind, S., and Wittmann, C. (2011). Biobased production of the platform chemical 1, 5-diaminopentane. Appl. Microbiol. Biotechnol. 91, 1287-1296.

Kosakai, Y., Soo Park, Y., and Okabe, M. (1997). Enhancement of L+-lactic acid production using mycelial flocs of Rhizopus oryzae. Biotechnol. Bioeng. 55, 461-470.

Krystynowicz, A., Czaja, W. Wiktorowska-Jezierska, A., Goncalves-Miskiewicz, M., Turkiewicz, M., and Bielecki, S. (2002). Factors affecting the yield and properties of bacterial cellulose. J. Ind. Microbiol. Biotechnol. 29, 189-195.

Lee, J. W., Kim, H. U., Choi, S., Yi, J., and Lee, S. Y. (2011a). Microbial production of building block chemicals and polymers. Curr. Opin. Biotechnol. 22, 758-767.

Lee, J. W., Kim, T. Y., Jang, Y. S., Choi, S., and Lee, S. Y. (2011b). Systems metabolic engineering for chemicals and materials. Trends Biotechnol. 29, 370-378.
Lee, J., Na, D., Park, J., Lee, J., Choi, S., and Lee, S. (2012). Systems metabolic engineering of microorganisms for natural and non-natural chemical. Nat. Chem. Biol. 8, 536-546.

Lee, S. Y., Choi, J. I., and Wong, H. H. (1999). Recent advances in polyhydroxyalkanoate production by bacterial fermentation: minireview. Int. J. Biol. Macromol. 25, 31-36.

Le Vo, T., Kim, T., and Hong, S. (2012). Effects of glutamate decarboxylase and gamma-aminobutyric acid (GABA) transporter on the bioconversion of GABA in engineered Escherichia coli. Bioprocess Biosyst. Eng. 35, 645-650.

Leonard, E., Runguphan, W., O'Connor, S., and Prather, K. J. (2009). Opportunities in metabolic engineering to facilitate scalable alkaloid production. Nat. Chem. Biol. 5, 292-300.

Lunt, J. (1998). Large-scale production, properties and commercial applications of polylactic acid polymers. Polym. Degrad. Stabil. 59, 145-152.

Martens, J. H., Barg, H., Warren, M. J., and Jahn, D. (2002). Microbial production of vitamin B-12. Appl. Microbiol. Biotechnol. 58, 275-285.

Martin, C. H., Nielsen, D. R., Solomon, K. V., and Prather, K. L. J. (2009). Synthetic metabolism: engineering biology at the protein and pathway scales. Chem. Biol. 16, 277-286.

Mazumdar, S., Clomburg, J. M., and Gonzalez, R. (2010). Escherichia coli strains engineered for homofermentative production of D-lactic acid from glycerol. Appl. Environ. Microbiol. 76, 4327-4336.

McKenna, R., and Nielsen, D. R. (2011) Styrene biosynthesis from glucose by engineered E. coli. Metab. Eng. 13, 544-554.

Mendez-Perez, D., Begemann, M. B., and Pfleger, B. F. (2011). Modular synthase-encoding gene involved in alpha-olefin biosynthesis in Synechococcus sp. strain PCC (7002). Appl. Environ. Microbiol. 77, 4264-4267.

Mimitsuka, T., Sawai, H., Hatsu, M., and Yamada, K. (2007). Metabolic engineering of Corynebacterium glutamicum for cadaverine 
fermentation. Biosci. Biotechnol. Biochem. 71, 2130-2135.

Nakamura, C. E., and Whited, G. M. (2003). Metabolic engineering for the microbial production of 1, 3propanediol. Curr. Opin. Biotechnol. 14, 454-459.

Nexant Chem Systems. (2009). New Process Evaluation and Research Program: Nylon 6 and Nylon 6, 6. San Francisco, CA: Nexant.

Nielsen, D. R., Yoon, S. H., Yuan, C. J., and Prather, K. L. (2010). Metabolic engineering of acetoin and meso-2, 3-butanediol biosynthesis in E. coli. Biotechnol. J. 5, 274-284.

Niu, W., Draths, K. M., and Frost, J. W. (2002). Benzene-free synthesis of adipic acid. Biotechnol. Prog. 18, 201-211.

Pawlowski, G., Dammel, R., Eckes, C., Lindley, C. R., Meier, W., Przybilla, K. J., Roschert, H., and Spiess, W. (1991). Substituted polyhydroxystyrenes as matrix resins for chemically amplified deep uv resist materials. Microelectron. Eng. 13, 29-32.

Pei, L., Schmidt, M., and Wei, W. (2011). "Conversion of biomass into bioplastics and their potential environmental impacts," in Biotechnology of Biopolymers, ed M. Elnashar (Rijeka, Croatia: InTech), 57-74.

Peralta-Yahya, P. P., and Keasling, J. D. (2010). Advanced biofuel production in microbes. Biotechnol. J. 5, 147-162.

Phillips, A. L. (2008). Bioplastics boom. Am. Sci. 96, 109.

Plastics Europe. (2011). Plastics Europe Market Research Group, PlasticsThe Facts 2011. Brussels, Belgium: Plastics Europe.

Qian, Z. G., Xia, X. X., and Lee, S. Y. (2009). Metabolic engineering of Escherichia coli for the production of putrescine: a four carbon diamine. Biotechnol. Bioeng. 104, 651-662.

Qian, Z. G., Xia, X. X., and Lee, S. Y. (2011). Metabolic engineering of Escherichia coli for the production of cadaverine: a five carbon diamine. Biotechnol. Bioeng. 108, 93-103.

Qi, W. W., Vannelli, T., Breinig, S., Ben-Bassat, A., Gatenby, A. A., Haynie, S. L., and Sariaslani, F. S. (2007). Functional expression of prokaryotic and eukaryotic genes in Escherichia coli for conversion of glucose to p-hydroxystyrene. Metab. Eng. 9, 268-276.

Rathnasingh, C., Raj, S. M., Jo, J. E., and Park, S. (2009). Development and evaluation of efficient recombinant Escherichia coli strains for the production of 3-hydroxypropionic acid from glycerol. Biotechnol. Bioeng. 104, 729-739.

Rathnasingh, C., Raj, S. M., Lee, Y., Catherine, C., Ashok, S., and Park, S. (2012). Production of 3hydroxypropionic acid via malonylCoA pathway using recombinant Escherichia coli strains. J. Biotechnol. 157, 633-640.

Reddy, G., Altaf, M., Naveena, B. J., Venkateshwar, M., and Kumar, E. V. (2008). Amylolytic bacterial lactic acid fermentation-a review. Biotechnol. Adv. 26, 22-34.

Reinecke, F., and Steinbuchel, A. (2009). Ralstonia eutropha strain H16 as model organism for PHA metabolism and for biotechnological production of technically interesting biopolymers. J. Mol. Microbiol. Biotechnol. 16, 91-108.

Revelles, O., Wittich, R.-M., and Ramos, J. L. (2007). Identification of the initial steps in d-lysine catabolism in Pseudomonas putida. J. Bacteriol. 189, 2787-2792.

Ro, D. K., Paradise, E. M., Ouellet, M., Fisher, K. J., Newman, K. L., Ndungu, J. M., Ho, K. A., Eachus, R. A., Ham, T. S., Kirby, J., Chang, M. C., Withers, S. T., Shiba, Y., Sarpong, R., and Keasling, J. D. (2006). Production of the antimalarial drug precursor artemisinic acid in engineered yeast. Nature 440, 940-943.

Rojas-Rosas, O., Villafana-Rojas, J., Lopez-Dellamary, F. A., NungarayArellano, J., and Gonzalez-Reynoso, O. (2007). Production and characterization of polyhydroxyalkanoates in Pseudomonas aeruginosa ATCC (9027). from glucose, an unrelated carbon source. Can. J. Microbiol. 53, 840-851.

Ross, P., Mayer, R., and Benziman, M. (1991). Cellulose biosynthesis and function in bacteria. Microbiol. Rev. 55, 35-58

Rude, M. A., Baron, T. S., Brubaker, S., Alibhai, M., Del Cardayre, S. B., and Schirmer, A. (2011). Terminal olefin (1-alkene) biosynthesis by a novel p450 fatty acid decarboxylase from Jeotgalicoccus species. Appl. Environ. Microbiol. 77, 1718-1727.

Sauer, M., Marx, H., and Mattanovich, D. (2008). Microbial production of 1, 3-propanediol. Recent Pat. Biotechnol. 2, 191-197.

Saxena, R. K., Anand, P., Saran, S., and Isar, J. (2009). Microbial production of 1, 3-propanediol: recent developments and emerging opportunities. Biotechnol. Adv. 27, 895-913.

Schirmer, A., Rude, M. A., Li, X., Popova, E., and Del Cardayre, S.
B. (2010). Microbial biosynthesis of alkanes. Science 329, 559-562.

Schneider, J., and Wendisch, V. (2010). Putrescine production by engineered Corynebacterium glutamicum. Appl. Microbiol. Biotechnol. 88, 859-868.

Schubert, P., Steinbuchel, A., and Schlegel, H. G. (1988). Cloning of the Alcaligenes eutrophus genes for synthesis of poly-betahydroxybutyric acid (PHB) and synthesis of PHB in Escherichia coli. J. Bacteriol. 170, 5837-5847.

Singh, M., Patel, S. K. S., and Kalia, V. C. (2009). Bacillus subtilis as potential producer for polyhydroxyalkanoates. Microbial. Cell Fact. 8, 38-48.

Smolke, C. D. (2009). The Metabolic Pathway Engineering Handbook Fundamentals. Boca Raton, FL: CRC Press/Taylor and Francis.

Sodergard, A., and Stolt, M. (2002). Properties of lactic acid based polymers and their correlation with composition. Prog. Polym. Sci. 27, 1123-1163.

Song, H., and Lee, S. Y. (2006). Production of succinic acid by bacterial fermentation. Enzyme Microb. Technol. 39, 352-361.

Sri. (2010). Styrene. Access Intelligence LLC Inc.

Steen, E. J., Kang, Y., Bokinsky, G., $\mathrm{Hu}, \mathrm{Z}$., Schirmer, A., Mcclure, A., Del Cardayre, S. B., and Keasling, J. D. (2010). Microbial production of fatty-acid-derived fuels and chemicals from plant biomass. Nature 463 , 559-562.

Straathof, A. J. J., Sie, S., Franco, T. T., and Van Der Wielen, L. A. M. (2005). Feasibility of acrylic acid production by fermentation. Appl. Microbiol. Biotechnol. 67, 727-734.

Suthers, P. F., and Cameron, D.C. (2000). Production of 3-hydroxypropionic acid in recombinant organisms. US Patent 6852517.

Tabor, C. W., and Tabor, H. (1985). Polyamines in microorganisms. Microbiol. Rev. 49, 81-99.

Takahara, I., Saito, M., Inaba, M., and Murata, K. (2005). Dehydration of ethanol into ethylene over solid acid catalysts. Catal. Lett. 105, 249-252.

Tateno, T., Okada, Y., Tsuchidate, T., Tanaka, T., Fukuda, H., and Kondo, A. (2009). Direct production of cadaverine from soluble starch using Corynebacterium glutamicum coexpressing alpha-amylase and lysine decarboxylase. Appl. Microbiol. Biotechnol. 82, 115-121.

Thakker, C., Martinez, I., San, K. Y., and Bennett, G. N. (2012)
Succinate production in Escherichia coli. Biotechnol. J. 7, 213-224.

Thompson, R. C., Swan, S. H., Moore, C. J., and Vom Saal, F. S. (2009). Our plastic age. Philos. Trans. R. Soc. B Biol. Sci. 364, 1973-1976.

Thorball, V. (1967). Styrofoam-an extruded polystyrene foam for low temperature insulation. Mod. Refrig. Air Cond. 70, 51.

Tseng, H. C., Harwell, C. L., Martin, C. H., and Prather, K. L. (2010). Biosynthesis of chiral 3-hydroxyvalerate from single propionate-unrelated carbon sources in metabolically engineered E. coli. Microb. Cell Fact. 9, 96.

Tseng, H. C., Martin, C. H., Nielsen, D. R., and Prather, K. L. (2009). Metabolic engineering of Escherichia coli for enhanced production of (R)- and (S)-3hydroxybutyrate. Appl. Environ. Microbiol. 75, 3137-3145.

Tsuruta, H., Paddon, C. J., Eng, D., Lenihan, J. R., Horning, T., Anthony, L. C., Regentin, R., Keasling, J. D., Renninger, N. S., and Newman, J. D. (2009). Highlevel production of amorpha-4, 11-diene, a precursor of the antimalarial agent artemisinin, in Escherichia coli. PLoS ONE 4:e4489. doi: 10.1371/journal.pone.0004489

US Department of Energy. (2002). Steam System Opportunity Assessment for the Pulp and Paper, Chemical Manufacturing, and Petroleum Refining Industries. Washington, DC.

US Department of Energy. (2004). Top Value Added Chemicals from Biomass. Washington, DC.

US Energy Information Administration. (2011). Available online at www.eia.gov.

Voloch, M., Jjansen, N. B., Ladisch, M., Tsao, G. T., Narayan, R., and Rodwell, V. W. (1985). "2, 3-Butanediol," in Comprehensive Biotechnology: The Principles, Applications and Regulations of Biotechnology in Industry, Agriculture and Medicine, 1st Edn, ed M. Moo-Young (New York, NY: Pergamon Press).

Wee, Y. J., Kim, J. N., and Ryu, H. W. (2006). Biotechnological production of lactic acid and its recent applications. Food Technol. Biotechnol. 44, 163-175.

Whited, G., Feher, F., Benko, D., Cervin, M., Chotani, G., Mcauliffe, J., Laduca, R., Ben-Shoshan, E., and Sanford, K. (2010). Development of a gas-phase bioprocess for isoprenemonomer production using metabolic pathway engineering. Ind. Biotechnol. 6, 152-163. 
Wierckx, N. J., Ballerstedt, H., De Bont, J. A., and Wery, J. (2005). Engineering of solvent-tolerant Pseudomonas putida S12 for bioproduction of phenol from glucose. Appl. Environ. Microbiol. 71, 8221-8227.

Wu, C., Koylinski, T., and Bozik, J. (1981). Preparation of styrene from ethylbenzene US Patent 4255599.

$\mathrm{Xu}$, J., and Guo, B. H. (2010). Poly(butylene succinate) and its copolymers: research, development and industrialization. Biotechnol. J. 5, 1149-1163.

Yang, T. H., Kim, T. W., Kang, H. O., Lee, S. H., Lee, E. J., Lim, S. C., Oh, S. O., Song, A. J., Park, S. J., and Lee, S. Y. (2010). Biosynthesis of polylactic acid and its copolymers using evolved propionate CoA transferase and PHA synthase. Biotechnol. Bioeng. 105, 150-160.

Yim, H., Haselbeck, R., Niu, W., Pujol-Baxley, C., Burgard, A., Boldt, J., Khandurina, J., Trawick, J. D., Osterhout, R. E., Stephen, R., Estadilla, J., Teisan, S., Schreyer, H. B., Andrae, S., Yang, T. H., Lee, S. Y., Burk, M. J., and Van Dien, S. (2011). Metabolic engineering of Escherichia coli for direct production of 1, 4-butanediol. Nat. Chem. Biol. 7, 445-452.

Zhou, S., Causey, T. B., Hasona, A., Shanmugam, K. T., and Ingram, L. O. (2003). Production of optically pure D-lactic acid in mineral salts medium by metabolically engineered Escherichia coli W3110. Appl. Environ. Microbiol. 69, 399-407.

Zhou, Y., Dominguez, J. M., Cao, N., Du, J., and Tsao, G. T. (1999). Optimization of L-lactic acid production from glucose by Rhizopus oryzae ATCC 52311. Appl. Biochem. Biotechnol. 77-79, 401-407.

Conflict of Interest Statement: The authors declare that the research was conducted in the absence of any commercial or financial relationships that could be construed as a potential conflict of interest.

Received: 04 June 2012; accepted: 08 August 2012; published online: 30 August 2012
Citation: Adkins J, Pugh S, McKenna $R$ and Nielsen DR (2012) Engineering microbial chemical factories to produce renewable "biomonomers". Front. Microbio. 3:313. doi: 10.3389/fmicb. 2012.00313

This article was submitted to Frontiers in Microbiotechnology, Ecotoxicology and Bioremediation, a specialty of Frontiers in Microbiology.

Copyright (C) 2012 Adkins, Pugh, McKenna and Nielsen. This is an open-access article distributed under the terms of the Creative Commons Attribution License, which permits use, distribution and reproduction in other forums, provided the original authors and source are credited and subject to any copyright notices concerning any third-party graphics etc. 